\title{
SOME NOTES ON THE MUSICAL LANDSCAPE
}

\section{Transforming Cultures eJournal, \\ Vol. 4 No 1 April 2009 http://epress.lib.uts.edu.au/journals/TfC}

\section{Theo van Leeuwen ${ }^{1}$}

\section{A brief history of the European landscape}

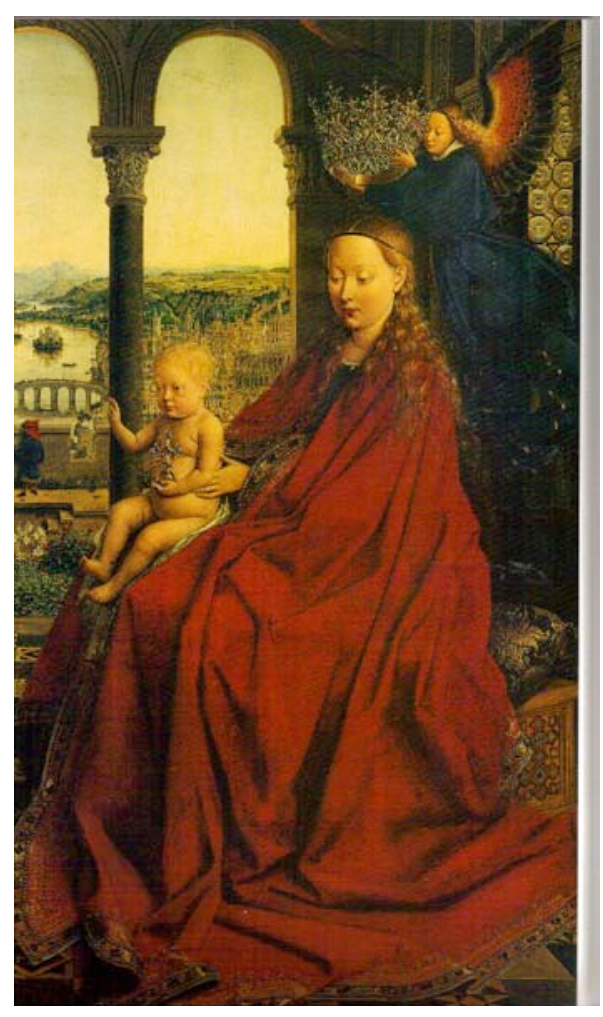

Jan van Eyck (c.1437) The Virgin with Chancellor Rolin (detail).

Copyright C 2002-2009<www.jan-van-eyck.org> (Creative Commons)

The poet and scholar Petrarch was the first European to climb a mountain for no other reason than to enjoy the view, in 1336.

But in fact he did not enjoy the experience. In a letter, he reported feeling anxious, overwhelmed by a longing for the familiar confines of his home town Arezzo.

\footnotetext{
${ }^{1}$ Professor Theo van Leeuwen is Dean for the Faculty of Arts and Social Sciences, University of Technology, Sydney.
} 
And he quoted St Augustine who had prophesied that "people will admire the height of mountains, the power of wide rivers, the vastness of oceans, the immenseness of the Universe, and in doing so, they will lose themselves." (quoted in Lemaire, 1970: 13) In the Renaissance, Europeans sought to break out of their immediate local environment, to move away from inward-looking reflection and meditation on religious matters. They cast their eyes on the far distance, seeking to explore the world, and their position in it.

But initially there was hesitation. It was hard to leave the trusted, familiar world. In many paintings of the time, the landscape is still seen from within, through a window. The view beckons, but the people in the painting still have their backs turned towards it.

Were they afraid of losing themselves?

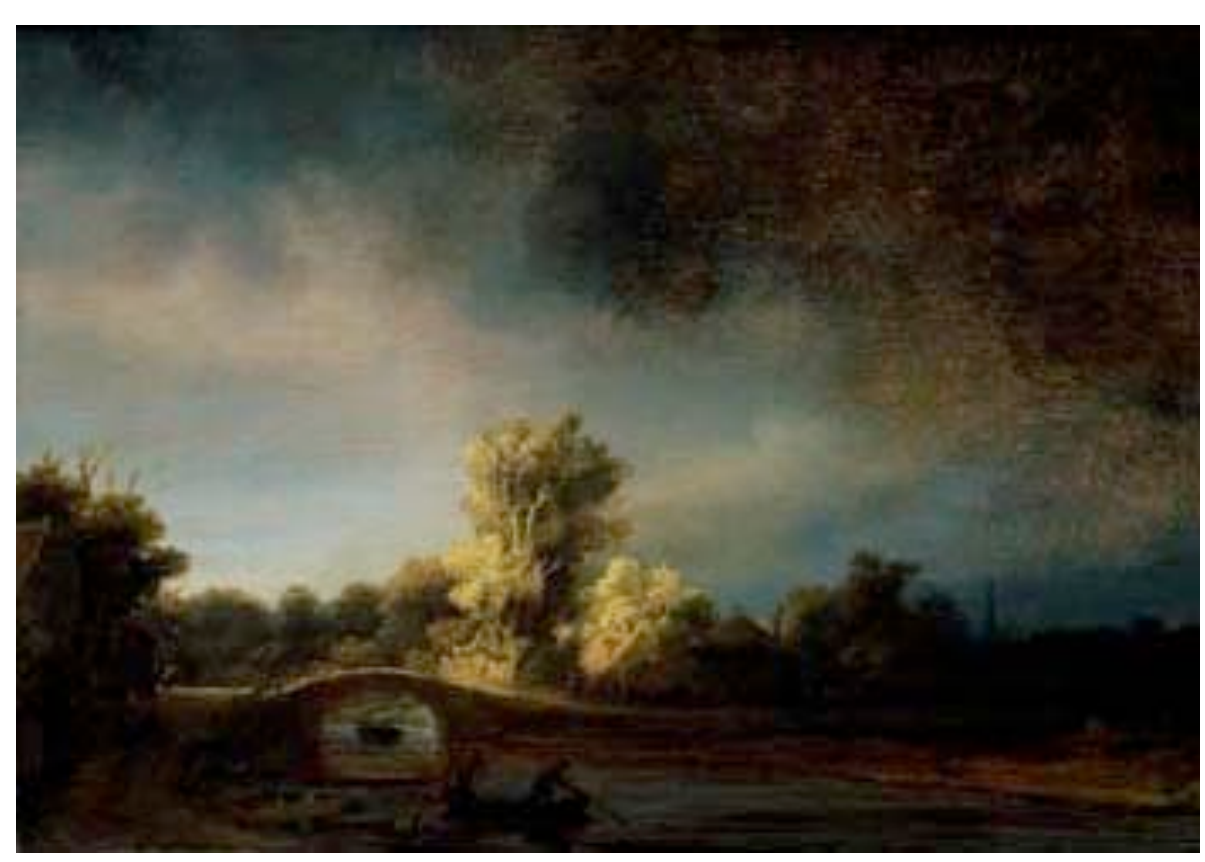

Rembrandt (late 1630s) Landscape with a stone bridge

Accessed from the Rijksmuseum, $<$ http://www.rijksmuseum.nl/aria/aria_assets/SK-A1935? page $=1 \&$ lang $=$ en\&context_space $=\&$ context_id $=>$

When the landscape became a genre on its own, as in Dutch landscape painting, the human lifeworld and the distant horizon were brought together in a unified whole.

Painting developed special techniques for doing so. Perspective unified the close and the distant in a single schema. Colour graduation differentiated the browns in the foreground from the blues in the background. 
On the one hand these paintings speak of the smallness of the human element in a vast world, under a vast sky. But vastness is no longer unsettling and anxiety-provoking. Human culture and nature have come together in a divine order that can be understood rationally, calculated, and trusted.

As painted landscapes developed, so did musical landscapes. A $16^{\text {th }}$ century Fantasia by John Mundy already depicted lightning (jagged melody fragments), thunder (rushing scales in the left hand) and 'fair weather' (a calmer melody). Like Dutch landscape paintings, the musical landscapes of the $17^{\text {th }}$ and $18^{\text {th }}$ century, for instance the landscapes of Vivaldi, Handel and Haydn, are naturalistic and calm, rich in detail birds, gently rolling countryside, animals, shepherds, villagers and hunters. And thunder and lightning are always followed by calmer weather.

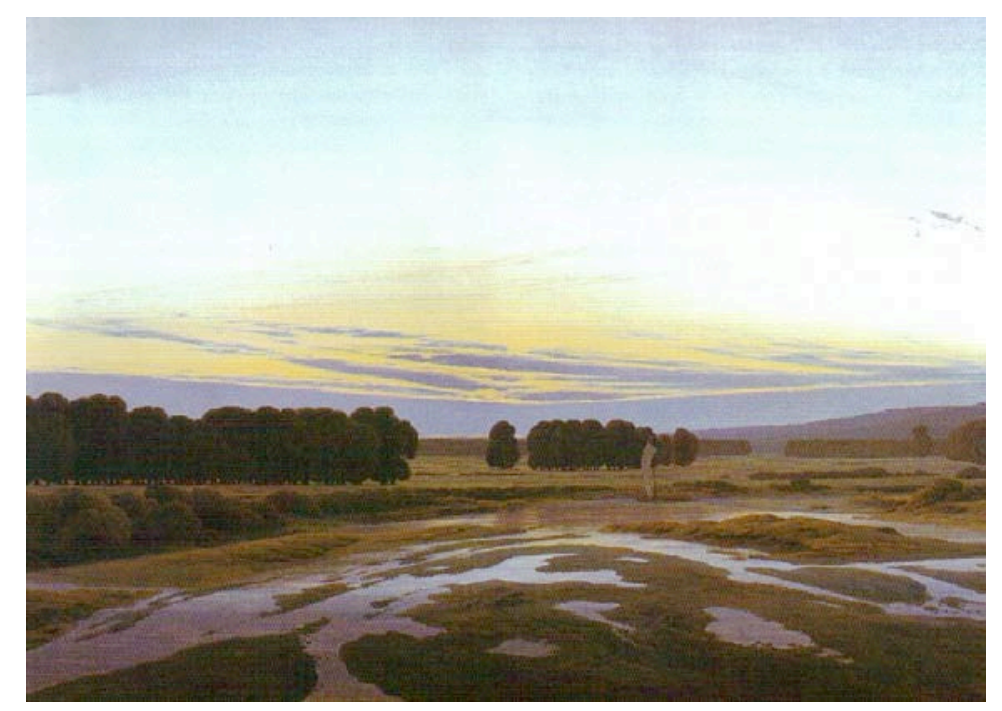

Caspar David Friedrich (1832) Large Enclosure near Dresden. Copyright 2009 artnet - the art world online.

In the Romantic era, nature is no longer a rationally ordered universe, but an ancient, awe-inspiring, and sometimes frightening 'other' which can bring people face to face with their deeper selves. Rousseau and Goethe walked in nature, seeking to come to themselves, but also experiencing wild mood fluctuations, exhilaration as well as depression.

In Romantic music such as Schumann's Dichterliebe there is often a striking contrast between the melody of the singer and the piano accompaniment. The melody then 
reflects the sombre mood of the poet wandering alone in the forest, while in the piano accompaniment nature retains its vigour, its colour and its equilibrium.

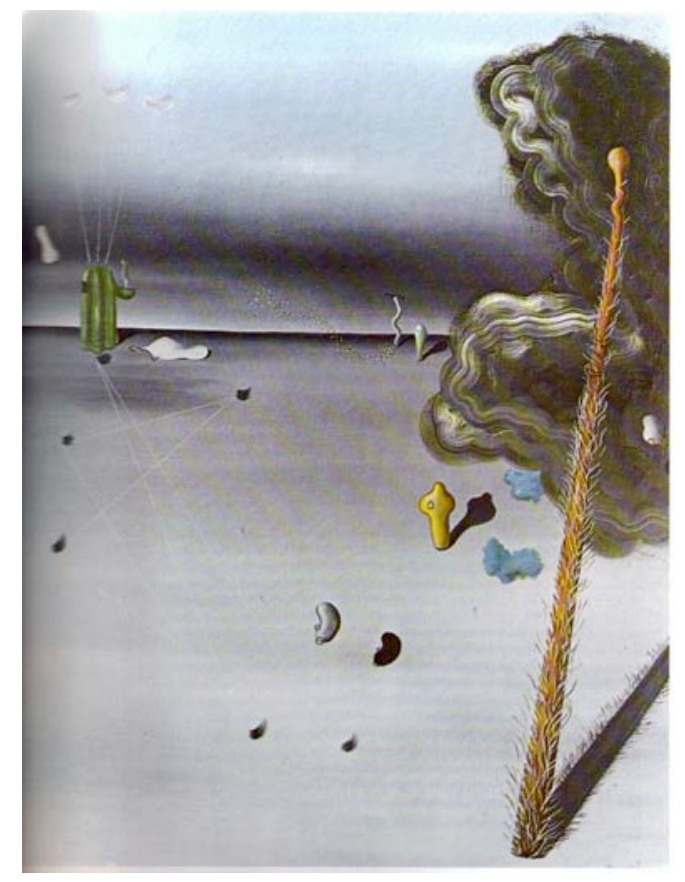

Yves Tanguy (1927) Mama, Papa is Wounded.

Tanguy is Copyright (C) 1999-2009 Olga's Gallery. All rights reserved. <www.abcgallery.com>

Twentieth century landscapes are often inhospitable, menacing deserts in which there is no place for human habitation. Vaughan Williams' Antarctic Symphony, for instance, evokes the silence and desolation of the Antarctic landscape through a wordless soprano, a female chorus and a wind machine, the ice formations through xylophones and glockenspiel, and the cracks in the icecaps through massive organ chords.

\section{How music paints landscapes}

As painting developed the means for the depiction of landscapes, so did music.

The most obvious of these is musical imitation. In principle, music can only imitate actions, and musical landscapes therefore tend to be depictions of actions, especially of actions that make a noise, such as the singing of birds, the pitter-patter of rain, the howling of the wind, and the roaring of the sea. But, slightly more abstractly, music can also depict the qualities of actions or things. Melodies can rise or fall - and rising or falling melodies can depict anything that rises or falls, whether literally or figuratively. 
Melodies can be staccato or legato, and so depict anything that is sharp, jagged, abrupt, and anything that is smooth, curved, connected.

At the same time as perspective began to bridge foreground and background in painting, creating the view from the 'lookout' point that would become such an important topos in the conception and experience of space in Western culture, music also developed perspective, through the introduction of variable dynamics. Dynamics is a natural signifier for distance, as sounds get softer the further they are away from the listener, and louder the closer they are to the listener.

In much Western music, melodies constitute semiotic actions. With or without words, melodies draw on the intonation patterns of human speech to put messages across. They are melodic acts, music's equivalent of the 'speech act'. They do things to or for the listener. They urge, soothe, seduce, and much more. The accompaniment then provides the setting in which this occurs. Such settings, in turn, can be of two kinds, depending on their rhythmic qualities. They can be unmeasured, ongoing, fluctuating sounds that do not have a defined rhythmic structure, or they can be measured, with a distinctive rhythmical structure and a regularly recurring beat or accent. Human action is by nature rhythmical and so an accompaniment in measured time can be said to relate to action to represent it as well as to facilitate it, for instance in dance, or in 'work songs'. Unmeasured time then contrasts to this by being 'not human', which, depending on the context, can signify 'nature', 'outer space', the 'divine', or anything else that can be constructed as 'not human'.

To this brief overview of resources for the musical depiction of landscapes, sound recording and mixing technologies should be added, as they, too, can be used for dynamic and timbral ('tone colour') variation, and for the location of sounds in space.

\section{Two landscapes by Charles Ives}

In the $20^{\text {th }}$ century, the musical landscape has come to play an important role in film music, often in the rather stereotypical forms which Adorno and Eisler have so eloquently criticized:

Landscape shots without action seem to call for musical accompaniment, which then conforms to stale patterns. Mountain peaks invariably invoke strong tremolos 
punctuated by a signal-like horn motif. The ranch to which the virile hero has eloped with his sophisticated heroine is accompanied by forest murmurs and a flute melody. A slow waltz goes with a moonlit scene in which a boat drifts down a river lined with weeping willows (1994: 13).

They concluded that "these associative patterns are so familiar that there is really no illustration of anything but only the elicitation of the automatic response 'Aha, nature!'”

But musical landscapes need not be clichéd. In Charles Ives' The Housatonic at Stockbridge, we first hear a haze of strings, very soft, atonal, and unmeasured, suggesting the river Housatonic, with the early morning mist still drifting over it. Then a horn melody enters, alluding to a hymn, and so suggesting the singing in a chapel, on the other side of the river. Initially the two elements seem to be in harmony, but gradually the sounds of nature grow stronger until they engulf and overwhelm the hymn, at which point the piece ends, unresolved.

Ives has described this musical landscape in words as well:

A Sunday morning walk that Mrs Ives and I took near Stockbridge, the summer after we were married. We walked in the meadows along the river, and heard the distant singing from the Church across the river. The mist had not entirely left the riverbed and the colours, the banks and the trees were something that one would always remember (quoted in Mellers, 1964: 45)

In Central Park in the Dark, Ives again used unmeasured and atonal orchestral textures to signify nature, in this case the park, then mixing in the sounds of the city - cars, trains, the shouts of newspaper sellers, and so on. Again, nature wins out, and, as Mellers put it "one is not sure whether the man-made noises, against the eternal hum and simmer of nature, are courageous or pathetically desperate" (ibid: 46).

In Rembrandt's time the human element in the landscape was small and humble, yet integrated. In Ives' American landscapes of the early $20^{\text {th }}$ century, that integration has been disturbed. Nature turns out to be stronger, overwhelming the sounds of human settlement. 
Whether in the work of painters or composers, landscapes not only depict, they also have something to say about the relation between humans and the world in which they live.

\section{References}

Adorno, T. and Eisler, H. (1994 [1947]) Composing for the Films. London: Athlone Press.

Lemaire, T. (1970) De filosofie van het landschap. Bilthoven: Ambo.

Mellers, W. (1964) Music in a New Found Land, London: Faber and Faber. 